\title{
TRANSITION OF ASSESSMENT TOOLS IN MEDICAL EDUCATION
}

\author{
Khushbu Adhikari, ${ }^{1}$ Shailesh Mani Pokharel ${ }^{2}$
}

\begin{abstract}
Medical education is on an advancement in recent years in Nepal. Our ultimate goal as a medical educationist is to produce a confident "Medical Graduate" who are capable to provide health care to the people belonging to different regions of our country. The curriculum for the medical program helps us achieve this goal. The effectiveness of the curriculum taught is assessed by various methods. There are two types of assessment namely formative and summative assessment. Of the various competencies expected out of an undergraduate only few are assessed in the routine internal and summative assessment examinations. The first and second generation tools such as viva voce and structured essay type questions evaluate the clinical reasoning without addressing other competencies such as social skills. The inadequacy in these assessment methods can hinder our way to achieving our goal. Social skills like communication skills, attitude, professionalism, leadership qualities, and skills of healing patients rather than just treating the disease is to be emphasized and addressed. Hence, third generation assessment like 360 degree assessment, experiential assessment, and portfolio can help us achieve our goal of creating efficient medical graduates which incorporates assessment of social skills as well.
\end{abstract}

KEYWORDS Competency, formative assessment, portfolio assessment, summative assessment

1. Department of Periodontology and Oral Implantology, Universal College of Medical Sciences, Bhairahawa, Nepal

2. Department of Ophthalmology, B.P. Koirala Institute of Health Sciences, Dharan, Nepal

DOI: https://doi.org/10.3126/jucms.v6i2.22499

\author{
For Correspondence \\ Dr. Khushbu Adhikari \\ Department of Periodontology \& Oral Implantology \\ Universal College of Medical Sciences \\ Bhairahawa, Nepal \\ E-mail: adhkhush@gmail.com
}




\section{INTRODUCTION}

Medical education has existed since long and is of utmost importance for producing competent surgeons and physicians in any country. Many changes have been made in the medical curriculum over the time in our country as well. The ultimate aim of medical education is to create a competent "Medical Graduate" who is capable to assume his or her role as a health care provider to the people.

Competency in medical education is defined as "the habitual and judicious use of communication, knowledge, technical skills, clinical reasoning, emotions, values and reflection in general practice for the benefit of the individual and community being served". ' Competence depends on engaging in clinical reasoning utilizing expert scientific, clinical, and humanistic judgment..$^{2-5}$ It is a known fact that students learn only what is important from examination point of view and what is assessed. ${ }^{6}$ This results in a bookish knowledge which they cannot apply practically in a given situation. ${ }^{7}$ Assessment is an integral part of the curriculum, as it determines the success and failures of individuals in any field. In the United States, medical students are assessed on the ACGME (Accreditation Council for Graduate Medical Education) Model which outlines six major competencies, desirable of a physician. These include medical knowledge, communication and interpersonal skills, patient care, system based practice and procedural skills.,

If we look at the current curriculum of undergraduate medical education in universities of our country, there is hardly any emphasis on assessment of professional competencies. But certainly things have moved in a better and progressive direction from before.

Ideally, the assessment of students' professional skills should provide insight into what he does habitually when not being observed along with his ability to adapt to changing environment while improving his overall performance and generating new ideas to better the field. Hence, the important role of assessment in further development of multiple dimensions of the medical profession is emphasized.

\section{ASSESSMENT METHODS}

Assessment methods can be formative or summative. Summative assessment is clearly differentiated from formative assessment as examination which will guide the students and offer continuous feedback. The competence, fitness to practice or qualification for advancement to higher levels of responsibility of an individual is judged as a whole. There is comparison with peers and results in terms of pass / fail which covers broad range of subjects at the end of the course only. ${ }^{10}$ It does not test the performance of an individual in depth on a regular basis but only on a given day. Although summative assessments are intended to provide professional self-regulation and accountability, it may force them to learn without actually learning and also act as a barrier to further practice or training. ${ }^{11}$ Also, summative assessment may not provide sufficient feedback to drive learning. ${ }^{12}$ Qualifying exams are the example of summative assessment.

On the other hand, "the process used by the teachers and students to recognize and respond to student learning in order to enhance the skills, during the learning" is defined as formative assessment. ${ }^{13}$ It guides the learner who is approaching a relatively unstructured body of knowledge and reinforces students' intrinsic motivation to learn and inspire them to set higher standards for themselves. ${ }^{14}$ Internal assessment are the examples of formative assessment.

Van der Vleuten ${ }^{15}$ has stated five criteria for a particular method of assessment to be useful. They are: reliability (the degree to which the measurement is accurate and reproducible), validity (whether the assessment measures what it claims to measure), impact on future learning and practice, acceptability to learners and faculty, and cost. Most of the medical schools still use the first generation assessment tools (Table 1) that hardly allows testing of most competencies desirable of a physician. Universities in India have introduced the second generation tools, such as objective structured clinical/practical examination (OSCE/OSPE) which specifically aims at testing medical practice and communication skills. ${ }^{16}$ These tools though permit evaluation of certain competencies, yet the overall approach and methodology has a major drawback of not being contextual.

Currently, assessment is broadly classified into two types:

1. Theory examination

2. Practical examination

\section{Theory examination:}

Theory examinations mainly assess the knowledge domain of the students with written tests which consists of essay questions, short notes and short answers. These assessment methods have the advantage of being relatively easy to frame and test knowledge and reasoning with a major disadvantage of limited range of application and lack of objectivity. Multiple-choice questions (MCQs) may also create situations in which an examinee can answer a question by recognizing the correct option, but could not have answered it in the absence of options. ${ }^{17,18}$ This effect, called cueing, is especially problematic when diagnostic reasoning is being assessed, because premature closure by arriving at a decision before the correct diagnosis has been considered, is a common reason for diagnostic errors in clinical practice. ${ }^{19,20}$ Short answer questions (SAQs) and structured essay questions (SEQs) avoid cueing but have certain limitations such as it is reliability dependent on training of graders and time consuming to grade, respectively. Multiple choice questions (MCQs) on the other hand, can result in cueing but can assess many content areas in relatively little time, has high reliability 
and can be graded by computer.

\section{Practical examination:}

The practical exams include long case, short case, spotting, viva-voce, objective structured clinical examination (OSCE). These assessment patterns help in assessing verbal skills and may also assess their interaction skills, ability to apply their knowledge and problem solving skills. ${ }^{21}$ In direct observations with checklists for ratings or oral examinations, feedback is provided by credible experts but selective rather than habitual behaviors are observed and is relatively time consuming. The "long case" 22 is also one such example where students are directly observed and assessed more frequently whereas oral examinations are time consuming and subjective, sex and race bias have been reported. ${ }^{10}$ OSCE has disadvantages as timing and setting maybe artificial. It is expensive but tailored to educational goals and ratings. Standardized patients with objective structured practical exams will help to assess student's clinical skills, interpersonal behavior, and communication skills. Interactions with standardized patients can be tailored to meet specific educational goals, and the standardized patients can reliably rate students' performance. The observing faculty can offer additional insights on student's clinical judgment, overall coherence of the history taking or physical examination and attitudes like empathy. Surgical specialties have initiated a more objective and quantifiable measure of technical skill proficiency known as the Imperial College Surgical Assessment Device (ICSAD). It is a hand motion analysis device designed to evaluate hand motion efficiency in surgeons along with manual dexterity. Construct validity has been established for different measurements produced by the ICSAD in open, laparoscopic, and micro-surgery. ${ }^{23,}{ }^{24}$ The Objective Structured Assessment of Technical Skills (OSATS) is another assessment of objective skill, used by the University of Toronto since the $1990 s^{23,}{ }^{25}$ It uses bench model simulation consisting of two components, an operation-specific checklist and a global rating scale and was reported to be proportional to the maturity of surgical skills.

\section{Downside of current assessment methods:}

Knowledge, recall, clinical reasoning, analytical skills and to some extent the communication skills are assessed by the current methods. But in a field involving wider scope and competencies, communication, attitude, professionalism, leadership qualities, working as a team and inclination to scientific research are the key areas that has to be addressed. Providing timely feedback to students and focusing on the ways and means to improve learning and acquisition of the necessary competencies is of utmost importance.

\section{Newer assessment methods:}

There has been significant development of assessment in medical education during the last decade. The progression of methods has moved from simple to more sophisticated assessment strategies. As already stated, formative assessment is an assessment for learning. ${ }^{10}$ and has tremendous educational implications on the degree of learning. It has been identified and recommended as an integral part of the curriculum. ${ }^{26}$ Formative assessment can be easily incorporated into the regular medical curriculum. During the clinical postings key competencies can be taught and assessed regularly along with effective feedback.

At present assessment of competency takes place in a simulated/artificial environment created especially for the purpose of examination. Competencies are not assessed in the real context where they are going to be practiced. Miller's pyramid of assessment is a hierarchical frame work of assessment, ${ }^{27}$ where 'doing' a task is ahead of 'showing how to do', 'knowing how to do', and 'knowing', in that sequence. Top of the pyramid consists of 'doing'; fails to mention the contextual relevance of this 'doing', which is more important.

A student may be able to 'do' a procedure on a dummy in a manner given in books and score full mark, but may lose confidence when faced with critical real life situations. The behavior of the student might differ in dealing with a simulated patient at an OSCE station as compared with patients in a busy OPD. Assessment therefore needs to be done in the context where the competency is to be practiced. ${ }^{28}$ This is possible only when the competencies are performed "in Context." The second generation assessment tools rely primarily on fragmented assessment, and evaluate only one or two competencies at a time. Also, competencies are dynamic and therefore needs to be assessed on a periodic basis rather than a onetime assessment. ${ }^{29}$ Third generation assessment tools like 360 degree, portfolio have been developed specifically to test these competencies.

Experiential assessment is something that can be carried out both inside and outside the class room or clinic. Performance of student is observed and assessed in a clinical or community settings, which would be an ideal setup. Structured direct observations with checklist can assess the communication and clinical skills including peer assessment. The feedback from the faculties in a timely manner will be insightful and beneficial to the learners. The "miniclinical-evaluation exercise" (mini-CEX) ${ }^{30}$ has been developed in order to directly observe the learners more frequently. The level of reliability will be same when compared with standardized patients as this structured exercises are done with actual patients under the observation of the supervising physician, ${ }^{22,31}$ yet encompassing a wider range of problems, physical findings, and clinical settings. In addition, video reviews offers a powerful means of evaluating and providing feedback on trainees' skills. ${ }^{32,33}$

Communication skills can be assessed in communities where the communities function as skills laboratories. The students can perform task on people in the community or patients 
which offers opportunity for self-assessment by peer or the faculty. Under patient management, decision making /making community diagnosis, inclination to scientific research and interpretation of statistical data can be learned through case studies, project work, exposure to role models, role play, workshops, and seminars. The same can be assessed by student's active participation in these learning sessions and faculty giving feedback on their performance.

Multi source $\left(360^{\circ}\right)$ assessments by peer, other members of the clinical team, and patients can help to assess students' work habits, capacity for teamwork, communication skills and interpersonal relationship. These assessment methods can be made highly effective by including narrative comments and constructive feedback. It should also be accompanied by good mentoring and follow up for effective intervention and implementation. ${ }^{34}$

Portfolio can be used to assess all aspects of competencies as these include documentation of and reflection about specific areas of a student's competence. ${ }^{35}$ Self-assessments, learning plans, and reflective essays are often included in portfolio. This assessment is intimately linked to self-directed learning and is the most useful tool for evaluating competencies such as practice-based improvement, use of scientific evidence in patient care, professional behavior and patient advocacy that are difficult to evaluate in other ways. ${ }^{36}$ Portfolio includes chart notes, referral letters, procedure logs, videotaped consultations, peer assessments, patient surveys, literature searches, quality-improvement projects, and other types of learning material.

Olle Ten Cate has defined Entrustable professional activities (EPA) as "unit of professional practice defined as task or responsibilities to be entrusted to the unsupervised execution by a trainee once he or she has attained sufficient specific competence. They are independently executable, observable, and measurable in their process and outcome, and therefore suitable for entrustment decisions. Proper sequencing of EPAs with increasing difficulty or sophistication can serve as a backbone for graduate medical education". ${ }^{37}$ Though subject to variability of student, examiner, context, and the activity itself, assessment of EPA, can be defined and utilized for graduate medical education program. It has emerged as the vital link between competencies and clinical practice. ${ }^{38}$

\section{CONCLUSION}

Assessment is an integral part of the curriculum in any field of study. It determines the success and failures of its recipients. There is a considerable gap in the current scenario between the goal of medical education and its assessment methods. Apart from the traditional summative and internal assessment methods, formative assessment has to be formally included in the medical curriculum to overcome this gap. Newer methods of formative assessment like portfolio, multi source assessment, and constructive feedback can definitely improve the learning and understanding of the undergraduate medical students while making medical education more appropriate for the current needs of the people.

\section{Table 1. Assessment tools in medical education ${ }^{39}$}

\begin{tabular}{|l|l|l|}
\hline $\mathbf{1}^{\text {st }}$ Generation Tools & $\mathbf{2}^{\text {nd }}$ Generation Tools & $\mathbf{3}^{\text {rd }}$ Generation Tools \\
\hline Theory: Essay type & Theory: & DOPS (direct observation of \\
question unstructured & Multiple choice question (MCQ) & practical skills) \\
Practical: & Modified Essay questions (MEQ) & Mini CEX (clinical evaluation \\
Long case & Short Answer Question (SAQ) & exercise) \\
Short case & Structured Essay Question & Portfolio-based assessment \\
Spotting & (SEQ) & $360^{\circ}$ (multisource assessment) \\
Oral Examination: & Practical: & EPA(entrustable professional \\
Viva-voce & Objective structured clinical & activities) assessment \\
Log-books & examination (OSCE) & \\
& Objective structured Practical & \\
& examination(OSPE) & \\
& Objective structured long & \\
& examination record (OSLER) & \\
\hline
\end{tabular}

\section{REFERENCES}

1. Epstein RM, Hundert EM. Defining and assessing professional competence. JAMA.2002;287:226-35.

2. Mandin H, Jones A, Woloschuk W, Harasym P. Helping students learn to think like experts when solving clinical problems. Acad Med. 1997; 72:173-79.

3. Friedman MH, Connell KJ, Olthoff AJ, Sinacore JM, Bordage G. Medical student errors in making a diagnosis. Acad Med. 1998; 73(suppl):S19-S21.

4. Feinstein AR. "Clinical Judgment" revisited: the distraction of quantitative models. Ann Intern Med. 1994; 120:799-805.

5. Downie RS, Macnaughton J, Randall R. Clinical Judgement: Evidence in Practice. Oxford, England: Oxford University Press; 2000.

6. Cooke M, Irby DM, Sullivan W, Ludmerer KM. American medical education 100 years after the Flexner report. N Engl J Med. 2006; 355:1339-44.

7. Gruppen LD, Frohna AZ. Clinical reasoning. In: Norman GR, Van Der Vleuten CP, Newble DI, eds. International handbook of research in medical education. Part 1. Dordrecht, the Netherlands: Kluwer Academic, 2002:205-30.

8. Batalden P, Leach D, Swing S, Dreyfus H, Dreyfus S. General competencies and accreditation in graduate medical education. Health Aff(Millwood. 2002; 21:103-11.

9. Farrell SE. Evaluation of student performance: clinical and professional performance. Acad Emerg Med. 2005; 12:302e610.

10. Epstein RM. Assessment in medical education. N Engl J Med. 2007 Jan 25; 356(4):387-96 
11. Sullivan W. Work and integrity: the crisis and promise of professio nalism in America. 2nd ed. San Francisco: Jossey Bass; 2005.

12. Schuwirth L, van der Vleuten C. Merging views on assessment. MedEduc. 2004; 38:1208-10.

13. Bell B, Cowie B. The Characteristics of Formative assessment in Science Education. Sci Educ. 2001; 85: 536-53.

14. Friedman Ben-David M. The role of assessment in expanding professional horizons. Med Teach. 2000; 22: 472-7.

15. Van Der Vleuten CPM. The assessment of professional competence: developments, research and practical implications. Adv Health Sci Educ. 1996; 1:41-67.

16. Gupta P, Dewan P, Singh T. Objective Structured Clinical Examination (OSCE) revisited. Indian Pediatr. 2010; 47: 911-20 .

17. Schuwirth LW, van der Vleuten CP. Different written assessment methods: what can be said about their strengths and weaknesses? Med Educ. 2004; 38:974-9.

18. Schuwirth LW, van der Vleuten CP, Donkers HH. A closer look at cueing effects in multiple-choice questions. Med Educ.1996; 30:44-9.

19. Friedman MH, Connell KJ, Olthoff AJ, Sinacore JM, Bordage G. Medical student errors in making a diagnosis. Acad Med.1998; 73(Suppl):S19-S21.

20. Graber ML, Franklin N, Gordon R. Diagnostic error in internal medicine. Arch Intern Med. 2005; 165:1493-9.

21. Ananthakrishnan N, Sethuraman KR, Santhosh K. (Editors). Curriculum. Medical Education Principles and Practice, 2nd ed. Alumni Association of NTTC JIPMER. Pondicherry: 2000; 107-11.

22. Norman G. The long case versus objective structured clinical examinations. BMJ. 2002; 324:748-9.

23. Reznick R, Regehr G, MacRae H, Martin J, McCulloch W. Testing technical skill via an innovative "bench station" examination. Am J Surg. 1997; 173: 226 -30.

24. Regehr G, MacRae H, Reznick RK, Szalay D. Comparing the psychometric properties of checklists and global rating scales for assessing performance on an OSCE-format examination. Acad Med. 1998; 73: 993-7.

25. Martin JA, Regehr G, Reznick R. Objective structured assessmentof technical skill (OSATS) for surgical residents. Br J Surg. 1997; 84(2):273-8.

26. Wood DF. Formative assessment. In: Swanwick T, Buckley G, editors. Understanding medical education: evidence, theory, and practice. London: Wiley-Blackwell; 2010; pp 259- 70.

27. Miller GE. The assessment of clinical skills/competence/ performance. Acad Med. 1990; 65(9 Suppl):S63-S67.
28. Klass D. Reevaluation of clinical competency. Am J Phys Med Rehabil. 2000; 79:481-86.

29. Leach DC. Competence is a habit. JAMA. 2002; 287:243-44

30. Norcini JJ, Blank LL, Duffy FD, Fortna GS. The mini-CEX: a method for assessing clinical skills. Ann Intern Med. 2003; 138: 476-81.

31. Van der Vleuten CP, Norman GR, De Graaff E. Pitfalls in the pursuit of objectivity: issues of reliability. Med Educ. 1991; 25:110-18

32. Epstein RM, Dannefer EF, Nofziger AC, et al. Comprehensive assessment of professional competence: the Rochester experiment. Teach Learn Med. 2004; 16:186-96.

33. Ram P, Grol R, Rethans JJ, Schouten B, Van der Vleuten C, Kester A. Assessment of general practitioners by video observation of communicative and medical performance in daily practice: issues of validity, reliability and feasibility. Med Educ. 1999; 33: 447-54

34. Norcini JJ. Peer assessment of competence. Med Educ. 2003; $37: 539-43$

35. Carraccio C, Englander R. Evaluating competence using a portfolio: a literature review and Web-based application to the ACGME competencies. Teach Learn Med. 2004; 16:381-7.

36. Singh T, Sood R. Workplace-based assessment: Measuring and shaping clinical learning. The National Medical Journal of India.2013;26(1):44.

37. Ten Cate O. Competency based education, entrustable professional activities, and the power of language. J Grad Med Educ. 2013; 5:6-7.

38. Ten Cate $\mathrm{O}$. Nuts and bolts of entrustable professional activities. J Grad Med Educ.2013; 5:157-8.

39 Piyush Gupta."Assessment in Medical Education: Time to move ahead.” Ann Natl Acad Med Sci (India), 2015, 51(4); 156-165. 